\title{
Values of Impulse Oscillometry in Healthy Mexican Children and Adolescents
}

\author{
Laura Gochicoa-Rangel MSc MD, Luis Torre-Bouscoulet MSc MD, David Martínez-Briseño MSc, \\ Luis Rodríguez-Moreno MD, Gabriela Cantú-González MD, and Mario H Vargas MSc MD
}

\begin{abstract}
BACKGROUND: The impulse oscillometry system (IOS) is increasingly used to evaluate lung function, but individual results must be compared with appropriate reference values. We aimed to obtain such reference values in Mexican children and adolescents. METHODS: Healthy subjects were recruited from kindergartens and schools after their parents signed a consent letter. Respiratory system impedances $(\mathrm{Zrs})$, resistances $(\mathrm{Rrs})$, and reactances $(\mathrm{Xrs})$ were measured at 5, 10, 15, and $20 \mathrm{~Hz}$, and the resonant frequency, reactance area, and difference between Rrs5 minus Rrs20 were also calculated. RESULTS: After exclusion of 4 children who were unable to perform an acceptable IOS recording, the final population comprised 283 children (153 females) 2.7-15.4 y of age. As a group, girls tended to have lower Xrs5 and higher Zrs20 and Rrs20 values. In bivariate analyses, all IOS variables had good correlation with age, height, and weight, and a better straightline fitting was obtained through data transformation to the $\log _{10}$ (age) or reciprocal (height and weight) values. Comparison of regression lines revealed small differences between males and females, especially in Xrs. Multiple linear regression analysis identified height as the most influential variable in the majority of IOS variables, but age also accounted for a moderate-to-large influence in the regression models in many IOS variables. CONCLUSIONS: In this study, we generated reference equations for each IOS variable in healthy children and adolescents. Although these equations were generated in a Mexican population, they are probably also applicable in other Latin American populations with the same ethnic background. Key words: impulse oscillometry; reference values; normal values; respiratory impedance; respiratory reactance; respiratory resistance. [Respir Care 2015;60(1):119-127. (C) 2015 Daedalus Enterprises]
\end{abstract}

\section{Introduction}

Pulmonary function tests are useful tools for diagnosis, evaluation, and follow-up of patients with respiratory dis-

\footnotetext{
Drs Gochicoa-Rangel, Torre-Bouscoulet, Rodríguez-Moreno, and CantúGonzález are affiliated with the Departamento de Fisiología Respiratoria, Instituto Nacional de Enfermedades Respiratorias Ismael Cosío Villegas, México DF; Dr Gochicoa-Rangel is also affiliated with the Centro de Evaluación del Paciente Asmático Infantil, Centro Médico Santa Teresa, Texcoco, Estado de México; Mr Martínez-Briseño is affiliated with the Departamento de Investigación en Epidemiología y Ciencias Sociales en Salud, Instituto Nacional de Enfermedades Respiratorias Ismael Cosío Villegas, México DF; and Dr Vargas is affiliated with both the Departamento de Investigación en Hiperreactividad Bronquial, Instituto Nacional de Enfermedades Respiratorias Ismael Cosío Villegas, México DF, and the Unidad de Investigación Médica en Enfermedades Respiratorias, Hospital de Pediatría, Centro Médico Nacional Siglo XXI, Instituto Mexicano del Seguro Social, México DF, México.
}

eases. Although spirometry is the most common of these tests, it demands the full cooperation of the subject, which is not always possible to obtain, especially in young chil-

\footnotetext{
Supplementary material related to this paper is available at http://www. rcjournal.com

Dr Gochicoa-Rangel submitted a preliminary version of this research as a thesis for her Master's in Science degree. The thesis is available online (http://tesis.unam.mx).

The authors have declared no conflicts of interest.

Correspondence: Mario H Vargas MSc MD, Departamento de Investigación en Hiperreactividad Bronquial, Instituto Nacional de Enfermedades Respiratorias, Tlalpan 4502, CP 14080, México DF, México. E-mail: mhvargasb@yahoo.com.mx.
}

DOI: $10.4187 /$ respcare.03374 
dren. The impulse oscillometry system (IOS) has been increasingly used due to its technical simplicity, because measurements are taken while the subject breathes at tidal volume. Briefly, the basis of this technique is as follows. ${ }^{1}$ The equipment uses a loudspeaker to send to the respiratory system a set of sound pulses or clicks at a rate of $\sim 5$ pulses/s. Each click is integrated by sinusoidal sound waves of varying frequencies (from 5 to $20 \mathrm{~Hz}$ ), overlapped in a square wave. Every click produces a pressure pulse $(\sim 2 \mathrm{~cm}$ $\mathrm{H}_{2} \mathrm{O}$ ) that causes small pressure and flow changes, which are superimposed onto the respective normal pressure and flow curves generated during tidal breathing. Using fast Fourier transform analysis, the equipment separates modifications occurring at specific frequencies $(5,10,15$, and $20 \mathrm{~Hz}$ ). In this analysis, the ratio of the pressure to flow changes yields the magnitude of the respiratory system impedance (Zrs), and because Zrs is a vector, its direction is determined by the lag phase between pressure and flow changes. Finally, decomposition of this vector in the real and imaginary axes yields the values for respiratory system resistance (Rrs) and reactance (Xrs), respectively. A valuable advantage of IOS, not shared by other techniques, is the possibility of partitioning the lung region being evaluated. Thus, whereas responses to $5 \mathrm{~Hz}$ are considered to represent impedance from total airways, those obtained at $20 \mathrm{~Hz}$ are preferentially generated in central airways. In addition, it is considered that Rrs mostly reflect resistive components (mainly due to resistance to air flow), whereas Xrs reflect inertive and capacitive components (mainly generated in lung and chest wall tissues). ${ }^{2}$

Several studies have shown that IOS correlates well with spirometric indexes, and that it is comparable to, or even more sensitive than, spirometry for detecting airway responses during bronchodilation or bronchoconstriction. ${ }^{3-5}$ Moreover, in patients with asthma, IOS is useful to assess therapeutic responses to corticosteroids ${ }^{6}$ and to predict ongoing loss of disease control. ${ }^{7}$ Thus, IOS appears to be a valuable tool for managing lung diseases. However, as with any other test, the result of an individual IOS test needs to be compared with an appropriate set of reference values generated in healthy population of the same age, gender, and ethnicity. ${ }^{8}$ To our knowledge, there are no published reports of IOS reference values for Mexican or Latin American children; thus, the aim of our study was to obtain such reference equations, evaluating potential differences between males and females.

\section{Methods}

The study protocol was approved by the science and bioethics committee of the Instituto Nacional de Enfermedades Respiratorias (approval C20-11). The study population was recruited from among alumni attending kindergartens and primary or secondary schools located in the

\section{QUICK LOOK}

\section{Current knowledge}

Impulse oscillometry is used to measure respiratory system resistance and reactance during normal tidal breathing. The advantages of this technique are simplicity and the ability to partition lung regions (central vs peripheral airways). Normal ranges across populations for impulse oscillometry are not yet defined.

\section{What this paper contributes to our knowledge}

In a study of 283 Mexican children and adolescents, reference equations for impulse oscillometry variables were generated using age, gender, and height and weight. Height was the most important variable followed by age. These equations may have generalizability across other ethnic groups of similarly aged subjects.

metropolitan area of Mexico City. After the corresponding educational authorities gave their permission for the study, a brief health questionnaire and a consent letter were sent to the parents. Children and adolescents whose parents agreed with their participation were included in the study if they fulfilled the following criteria: (1) without chronic illnesses including heart, liver, kidney, and respiratory diseases (asthma, wheezing, rhinosinusitis); (2) without past history of prematurity, pneumonia, bronchiolitis, or regular exposure to environmental tobacco or biomass smoke; (3) absence of any acute respiratory morbidity in the past 15 days; (4) without suspicion of sleep apnea/hypopnea syndrome or gastroesophageal reflux.

\section{Impulse Oscillometry Procedure}

IOS was carried out with commercial equipment (MSIOS, Erich Jaeger, CareFusion, San Diego, California). According to the manufacturer's instructions, volume and pressure calibration of the equipment was verified on a daily basis with a certified 3-L syringe (maximal variability $3 \%$ ) and with a pressure calibrator ( $0.2 \mathrm{kPa}$ impedance) with maximal pressure variability of $\pm 0.01 \mathrm{kPa}$. Additionally, linearity at 3 different flows $(<2,4-6$, and $>8 \mathrm{~L} / \mathrm{s}$ ) was corroborated on a weekly basis. On the day of the study, subjects were submitted to a physical examination, and their weight and standing height were measured (scales models 206 and 769, Seca, Hamburg, Germany). The IOS procedure was performed according to major recommendations published by several authors.9-11 Briefly, with the subject in the sitting position and wearing a nose clip, the procedure was explained in plain language and the child or adolescent was allowed to become accus- 
Table 1. Anthropometric Features in Healthy Children and Adolescents Submitted to Impulse Oscillometry System Measurement

\begin{tabular}{|c|c|c|c|c|c|c|c|}
\hline \multirow{2}{*}{ Variable } & \multicolumn{2}{|c|}{ All $(N=283)$} & \multicolumn{2}{|c|}{ Females $(n=153)$} & \multicolumn{2}{|c|}{ Males $(n=130)$} & \multirow{2}{*}{$P^{*}$} \\
\hline & Median & Q1, Q3 & Median & Range & Median & Range & \\
\hline \multicolumn{8}{|c|}{ Anthropometric features } \\
\hline Age (y) & 8.3 & $5.1,10.5$ & 8.0 & $2.7-15.2$ & 8.4 & $3.0-15.4$ & .38 \\
\hline Weight $(\mathrm{kg})$ & 25.5 & $18.9,34.6$ & 24.8 & $12.0-69.4$ & 26.2 & $13.6-76.6$ & .38 \\
\hline Height $(\mathrm{cm})$ & 125.0 & $109.0,137.3$ & 123.3 & $85.5-163.5$ & 125.1 & $93.0-170.8$ & .31 \\
\hline BMI $\left(\mathrm{kg} / \mathrm{m}^{2}\right)$ & 16.7 & $15.6,18.6$ & 16.7 & $13.1-27.8$ & 16.7 & $10.2-27.8$ & .85 \\
\hline \multicolumn{8}{|c|}{$\begin{array}{l}\text { * Comparison between males and females (Mann-Whitney U-test). } \\
\text { Q1 = quartile } 1 \\
\text { Q3 = quartile } 3 \\
\text { BMI = body mass index }\end{array}$} \\
\hline
\end{tabular}

tomed to the equipment. The subject was asked to breath into the equipment's mouthpiece, which was coupled with an antibacterial filter. While under quiet tidal breathing and with cheeks supported by a research collaborator, 3 IOS measurements were carried out, each lasting $30 \mathrm{~s}$ and performed $1 \mathrm{~min}$ apart. Acceptability criteria of the recording included lack of visually detected artifacts and a coherence (ie, correlation between input and output signals) of at least 0.6 at $5 \mathrm{~Hz}$ and 0.9 at $10 \mathrm{~Hz}$.

Variability of IOS results obtained in the same subject was assessed by 3 different approaches: (1) the intrameasurement coefficient of variation (im-CV), that is, the variability of the three 30-s IOS measurements used to average the final IOS result; (2) the within-occasion or short-term variability, that is, the comparison of 2 IOS results obtained 30 min apart; and (3) the between-occasion or longterm variability, that is, the comparison of 2 IOS results obtained $15 \mathrm{~d}$ apart. For the last 2 approaches, a group of 30 children under 6 y of age were randomly selected, and 2 additional IOS measurements were performed $30 \mathrm{~min}$ and $15 \mathrm{~d}$ later.

\section{Data Analysis}

IOS variables included in the analyses were Zrs, Rrs, and Xrs, all measured at 5, 10, 15, and $20 \mathrm{~Hz}$, as well as the resonant frequency (Fres), reactance area (AX), and difference between Rrs5 minus Rrs20 (DRrs5 - Rrs20). Degree of variability was evaluated for each IOS variable by using the coefficient of variation $(\mathrm{CV}=100 \times$ standard deviation/mean, expressed in percentage), and the coefficient of repeatability $(\mathrm{CR}=$ $1.96 \times \sqrt{\sum}\left[\mathrm{x}_{1}-\mathrm{x}_{2}\right]^{2} /[\mathrm{n}-1]$, expressed in the same units as the respective variable).

The majority of IOS variables did not follow normal distribution because they were skewed to the right (Zrs, Rrs, and AX) or left (Xrs). Thus, the nonparametric MannWhitney U-test was used to compare males and females; the Spearman rank correlation coefficient $\left(r_{S}\right)$ was used to evaluate associations between every IOS variable and age, height, or weight; and the Friedman test followed by the Wilcoxon signed-rank test with Bonferroni correction was used to evaluate changes of IOS values at $30 \mathrm{~min}$ and $15 \mathrm{~d}$. In the majority of bivariate regressions, data were transformed into the $\log _{10}$ (age) or reciprocal (height, weight) values to achieve better linearity. IOS values with standardized residuals larger than $\mathrm{z}=3.3$ were considered as potential outliers, and, after careful examination of individual cases, some of these values were eliminated from

Table 2. Values of Impulse Oscillometry System Parameters Measured in 283 Healthy Children and Adolescents

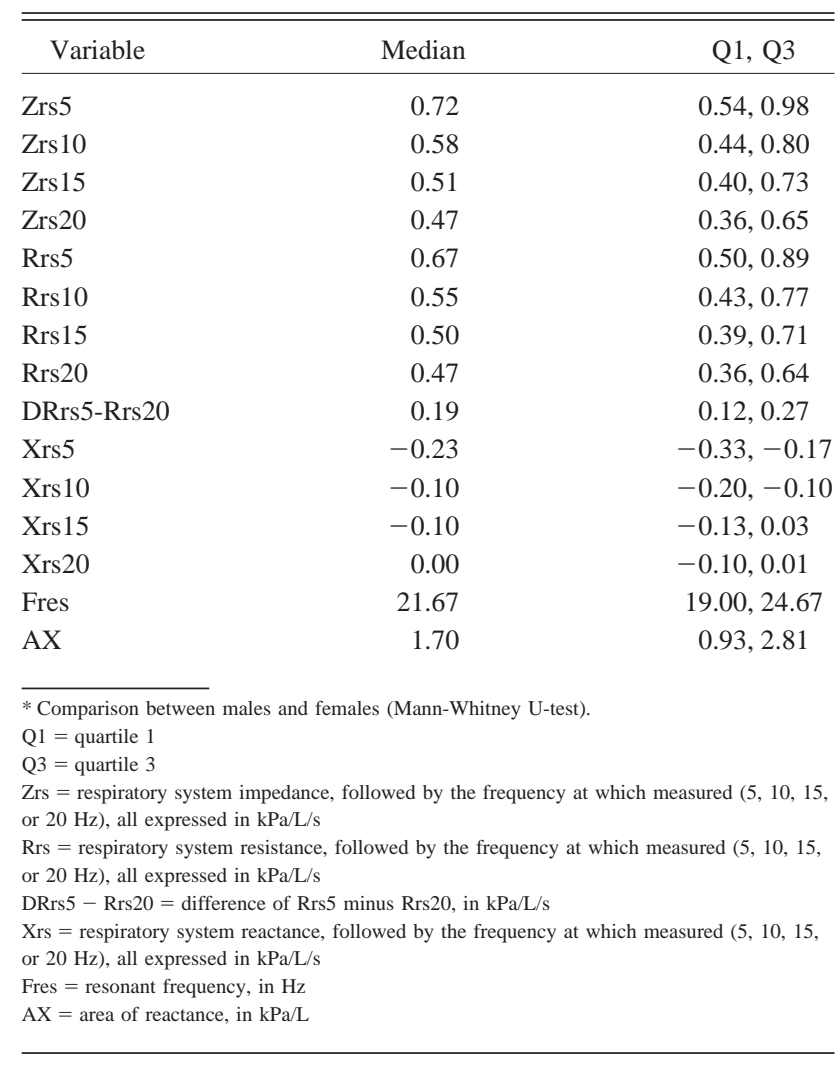




\section{Impulse Oscillometry in Healthy Children and Adolescents}

the analysis. Finally, multivariate linear regression was used to generate the reference equations for each IOS variable. Statistical significance was set at 2 -tailed $P<.05$.

\section{Results}

From 789 children whose parents accepted the participation of their child in the study, 502 did not fulfill one or more selection criteria, mainly because they had experienced an upper airway infection in the last 15 days or had been catalogued as having airway hyperresponsiveness or gastroesophageal reflux or had regular exposure to indoor wood smoke or tobacco smoke. In addition, 4 children were eliminated from the study because they did not perform acceptable IOS recordings. Thus, the final population comprised 283 children, aged 2.7-15.4 y, including 153 females and 130 males.

The anthropometric features of the study population can be observed in Table 1, and no differences could be detected between males and females. Table 2 contains the grouped values for each IOS variable. Comparison between genders showed that the only 3 variables close to reaching statistical significance were Xrs5, which was slightly lower in females (median [range], $-0.23[-0.73$ to -0.07$]$ vs males $-0.20[-0.67$ to -0.10$], P=.056$ ), as well as Zrs20 and Rrs20, which were slightly higher in females $(0.48$ [0.38 to 0.68 ] vs males 0.45 [0.36 to 0.61 ], $P=.083$, and 0.48 [0.21 to 1.10$]$ vs males 0.45 [0.21 to 0.95 ], $P=.085$, respectively, data not illustrated).

As can be seen in Table 3, in the baseline measurement, Zrs, Rrs, and Fres exhibited relatively small intrameasurement variability (im-CV $<10 \%$ ), whereas for DRrs5 - Rrs20, Xrs, and AX, the im-CV ranged from $20.8 \%$ to $62.6 \%$. The im-CV values did not differ between males and females (data not shown), and this pattern was essentially the same at $30 \mathrm{~min}$ and at $15 \mathrm{~d}$. Interestingly, evaluation of the percentage change of the additional measurements made in a subpopulation of 30 children under the age of $6 \mathrm{y}$ showed that respiratory impedances and resistances tended to be lower at $30 \mathrm{~min}$. Furthermore, this lower tendency reached statistical significance in Zrs20 and Rrs20 at day 15, and the lower values of Rrs20 probably explain concurrent widening of DRrs5 - Rrs20 at day 15 .

In bivariate analyses, all IOS variables had good correlation coefficients with age, height, and weight, ranging

Table 3. Variability of IOS Measurements in Healthy Children and Adolescents

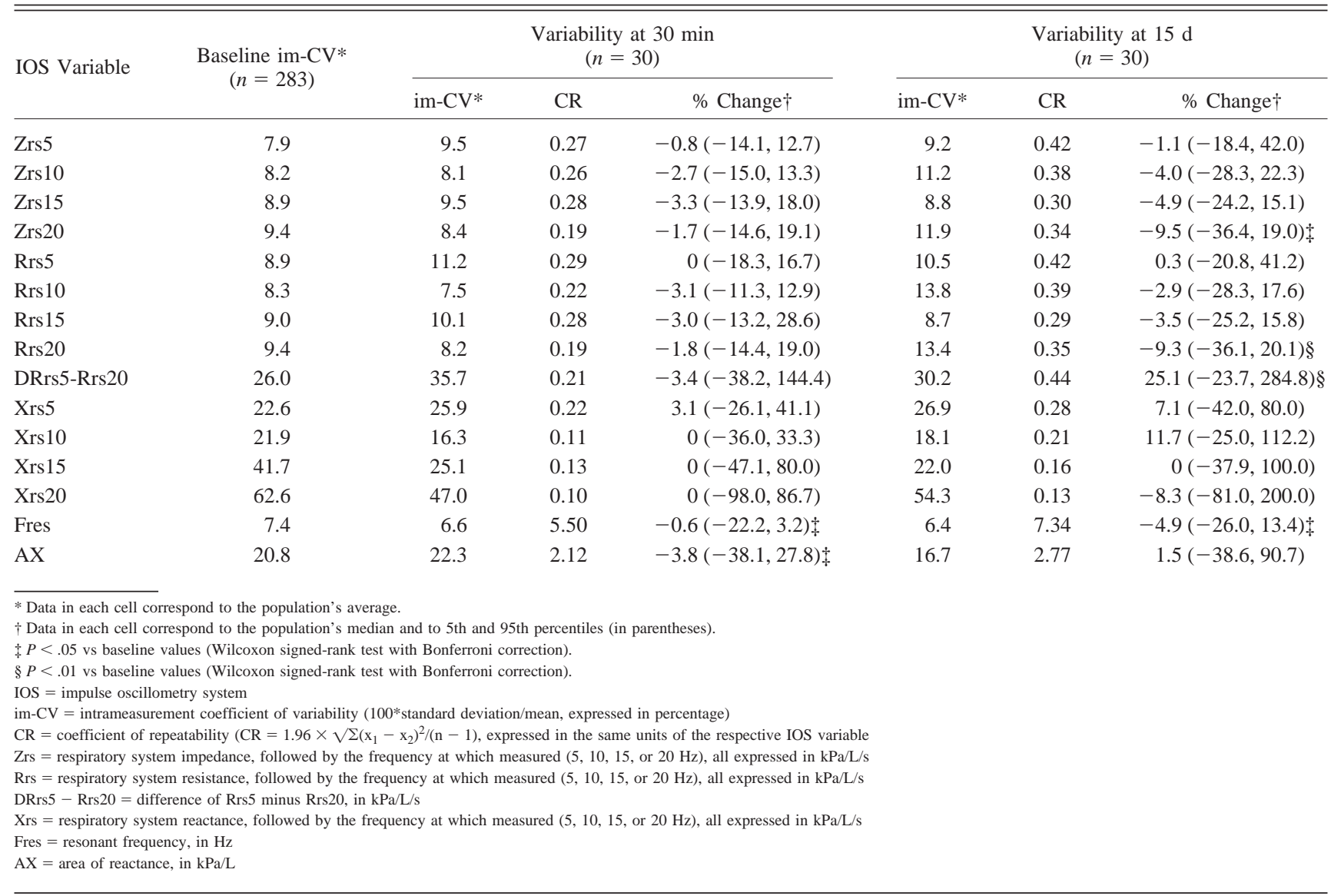


Table 4. Spearman's Correlation Coefficients Between Anthropometric and IOS Variables in 283 Healthy Children and Adolescents

\begin{tabular}{lccr}
\hline \hline & \multicolumn{3}{c}{ Spearman's } \\
IOS Variable & Age & Weight & Height \\
\cline { 2 - 4 } & -0.88 & -0.84 & -0.88 \\
Zrs5 & -0.89 & -0.84 & -0.88 \\
Zrs10 & -0.87 & -0.84 & -0.87 \\
Zrs15 & -0.85 & -0.81 & -0.85 \\
Zrs20 & -0.87 & -0.83 & -0.87 \\
Rrs5 & -0.88 & -0.83 & -0.88 \\
Rrs10 & -0.87 & -0.83 & -0.87 \\
Rrs15 & -0.85 & -0.81 & -0.85 \\
Rrs20 & -0.67 & -0.62 & -0.66 \\
DRs5-Rrs20 & 0.80 & 0.77 & 0.80 \\
Xrs5 & 0.79 & 0.74 & 0.78 \\
Xrs10 & 0.76 & 0.72 & 0.76 \\
Xrs15 & 0.77 & 0.73 & 0.77 \\
Xrs20 & -0.74 & -0.70 & -0.74 \\
Fres & -0.82 & -0.77 & -0.81 \\
AX & & & \\
\end{tabular}

$\overline{\mathrm{IOS}}=$ impulse oscillometry system

$\mathrm{Zrs}=$ respiratory system impedance, followed by the frequency at which measured $(5,10,15$, or $20 \mathrm{~Hz}$ ), all expressed in $\mathrm{kPa} / \mathrm{L} / \mathrm{s}$

$\mathrm{Rrs}=$ respiratory system resistance, followed by the frequency at which measured $(5,10,15$, or $20 \mathrm{~Hz}$ ), all expressed in $\mathrm{kPa} / \mathrm{L} / \mathrm{s}$

DRrs5 $-\operatorname{Rrs} 20=$ difference of Rrs5 minus Rrs20, in $\mathrm{kPa} / \mathrm{L} / \mathrm{s}$

$\mathrm{Xrs}=$ respiratory system reactance, followed by the frequency at which measured $(5,10,15$, or $20 \mathrm{~Hz}$ ), all expressed in $\mathrm{kPa} / \mathrm{L} / \mathrm{s}$

Fres $=$ resonant frequency, in $\mathrm{Hz}$

$\mathrm{AX}=$ area of reactance, in $\mathrm{kPa} / \mathrm{L}$ from $r_{S}=-0.62$ to $r_{S}=-0.89$ (Table 4). In nearly all cases, regression analyses corroborated that better straightline fitting (greater coefficients of determination) was achieved when data values were transformed into the respective $\log _{10}$ (age) or reciprocal (height and weight) values, as exemplified in Figure 1; thus, this data transformation was used in subsequent analyses. In the majority of regression analyses, 1 or 2 outliers were deleted, excepting for Fres and AX, where up to 6 outliers were eliminated. Through pairwise comparison of regression lines, small differences could be detected between males and females, either in their slopes and/or in their intercepts (see the supplementary figures at http://www.rcjournal.com). Because these differences achieved or were very close to achieving statistical significance, especially in Xrs, all reference values were evaluated separately by gender.

Multiple linear regression analysis identified height as the most influential variable in the majority of IOS variables, but age also accounted for a moderate-to-large influence in the regression models of many IOS variables, whereas body weight was excluded from nearly all of the regression models; thus, reference values were constructed considering age and height. The only exception was DRrs5 - Rrs20, because this variable achieved its highest correlation with age (without $\log _{10}$ transformation), and height did not improve the model; therefore, equation for this variable was a straight-line regression. The final equa-
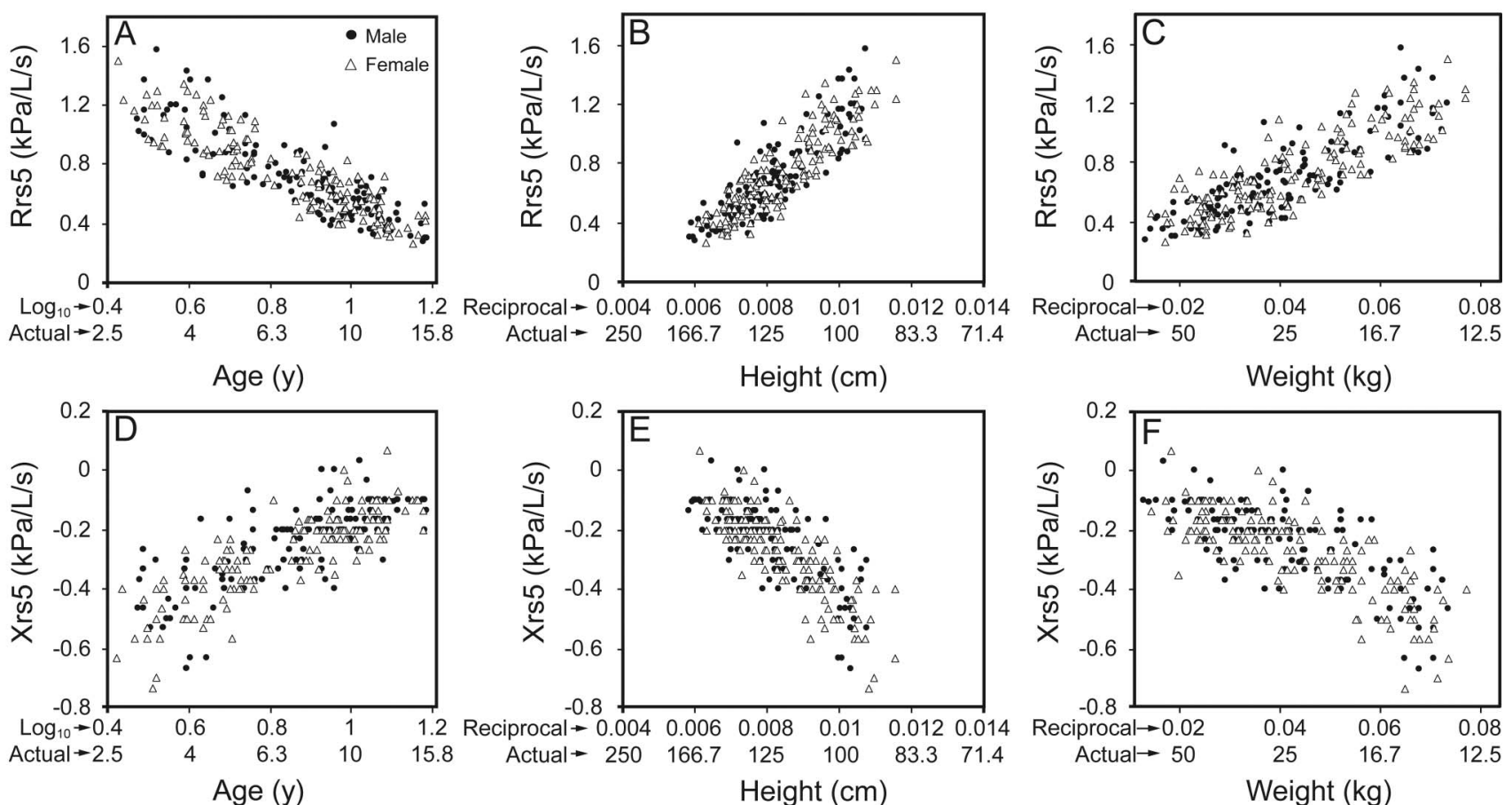

Fig. 1. Association of selected impulse oscillometry variables with age, height, and weight in a population of 283 healthy children and adolescents. Data corresponding to $x$-axes were transformed into the respective $\log _{10}$ (age) or reciprocal (height and weight) values to yield better linearity. Symbols correspond to male (filled circles) and female (empty triangles) subjects. 
Impulse Oscillometry in Healthy Children and Adolescents

Table 5. Equations for Calculating Reference Values of IOS Variables in 130 Healthy Male Children and Adolescents

\begin{tabular}{lcccrc}
\hline \hline IOS Variable & $\begin{array}{c}\text { A (Age } \\
\text { Coefficient) }\end{array}$ & $\begin{array}{c}\text { B (Height } \\
\text { Coefficient) }\end{array}$ & $\begin{array}{c}\text { C } \\
\text { (Constant) }\end{array}$ & r & RSD \\
\hline Zrs5 & $-0.694^{*}$ & $107.856^{*}$ & 0.476 & -0.87 & 0.1494 \\
Zrs10 & $-0.622^{*}$ & $78.317 \dagger$ & 0.514 & -0.87 & 0.1188 \\
Zrs15 & $-0.484^{*}$ & $86.227^{*}$ & 0.268 & -0.88 & 0.1051 \\
Zrs20 & $-0.377 \dagger$ & $82.941^{*}$ & 0.148 & -0.87 & 0.0974 \\
Rrs5 & $-0.636^{*}$ & $99.506^{*}$ & 0.443 & -0.86 & 0.1405 \\
Rrs10 & $-0.590^{*}$ & $75.807 \dagger$ & 0.488 & -0.87 & 0.1146 \\
Rrs15 & $-0.462^{*}$ & $83.927^{*}$ & 0.254 & -0.88 & 0.1012 \\
Rrs20 & $-0.367 \dagger$ & $82.162^{*}$ & 0.140 & -0.87 & 0.0965 \\
DRrs5-Rrs20 & $-0.0218^{*}$ & NA & 0.3864 & -0.60 & 0.0928 \\
Xrs5 & 0.228 & $-46.787 \dagger$ & -0.068 & 0.79 & 0.0784 \\
Xrs10 & $0.209 \dagger$ & -20.758 & -0.145 & 0.72 & 0.0613 \\
Xrs15 & $0.208 \dagger$ & -19.108 & -0.121 & 0.73 & 0.0587 \\
Xrs20 & $0.170 \dagger$ & -19.298 & -0.019 & 0.80 & 0.0419 \\
Fres & $-11.675 \dagger$ & 958.724 & 24.027 & -0.74 & 3.0244 \\
AX & $-3.938 \dagger$ & 340.493 & 2.635 & -0.78 & 0.9094 \\
& & & & &
\end{tabular}

Each equation corresponds to: $\operatorname{IOS}$ variable $=\mathrm{A} \times(\log$ of age in years $)+\mathrm{B} \times(1 /$ height in $\mathrm{cm})+\mathrm{C}$, excepting DRrs5 - Rrs20 $=\mathrm{A} \times($ age in years $)+\mathrm{C}$. The $\mathrm{z}$ score for an

individual subject can be calculated through the formula: $\mathrm{z}$ score $=$ (observed

value - predicted value)/RSD

$* P<.01$.

$\dagger P<.05$.

IOS $=$ impulse oscillometry system

RSD $=$ standard deviation of residuals

$\mathrm{r}=$ correlation coefficient

$\mathrm{Zrs}=$ respiratory system impedance, followed by the frequency at which measured $(5,10,15$, or $20 \mathrm{~Hz}$ ), all expressed in $\mathrm{kPa} / \mathrm{L} / \mathrm{s}$

Rrs $=$ respiratory system resistance, followed by the frequency at which measured $(5,10,15$, or $20 \mathrm{~Hz}$ ), all expressed in $\mathrm{kPa} / \mathrm{L} / \mathrm{s}$

DRrs5 $-\operatorname{Rrs} 20=$ difference of Rrs5 minus Rrs20, in $\mathrm{kPa} / \mathrm{L} / \mathrm{s}$

$\mathrm{NA}=$ not applicable

$\mathrm{Xrs}=$ respiratory system reactance, followed by the frequency at which measured $(5,10,15$, or $20 \mathrm{~Hz}$ ), all expressed in $\mathrm{kPa} / \mathrm{L} / \mathrm{s}$

Fres $=$ resonant frequency, in $\mathrm{Hz}$

$\mathrm{AX}=$ area of reactance, in $\mathrm{kPa} / \mathrm{L}$

tions for males and females are shown in Tables 5 and 6 , respectively.

In Figure 2, the curvilinear regression lines obtained in the present study were compared with already published reference equations in other populations.

\section{Discussion}

In the present study, a set of reference values for each IOS variable was obtained in a population of healthy children and adolescents. As occurs with other pulmonary function tests, we found that IOS values progressively changed as children grew up. In many of the published IOS reference equations, such as those proposed by Park et al, ${ }^{12}$ Lee et al, ${ }^{13}$ Hellinckx et al, ${ }^{14}$ and Frei et al, ${ }^{15}$ the relationship between IOS variables and anthropometric parameters such as height was found to follow a straight-line fitting. This is in contrast with our results, in which a curvilinear fitting was observed, and might be explained
Table 6. Equations for Reference Values of IOS Variables in 153 Healthy Female Children and Adolescents

\begin{tabular}{lcccrc}
\hline \hline IOS Variable & $\begin{array}{c}\text { A (Age } \\
\text { Coefficient) }\end{array}$ & $\begin{array}{c}\text { B (Height } \\
\text { Coefficient) }\end{array}$ & $\begin{array}{c}\text { C } \\
\text { (Constant) }\end{array}$ & r & RSD \\
\hline Zrs5 & $-0.595^{*}$ & $130.320^{*}$ & 0.214 & -0.90 & 0.1374 \\
Zrs10 & $-0.608^{*}$ & $88.681^{*}$ & 0.428 & -0.90 & 0.1107 \\
Zrs15 & $-0.487^{*}$ & $85.634^{*}$ & 0.285 & -0.90 & 0.1020 \\
Zrs20 & $-0.474^{*}$ & $69.140^{*}$ & 0.361 & -0.88 & 0.0980 \\
Rrs5 & $-0.736^{*}$ & $78.861^{*}$ & 0.702 & -0.89 & 0.1221 \\
Rrs10 & $-0.579 *$ & $80.283^{*}$ & 0.450 & -0.91 & 0.1004 \\
Rrs15 & $-0.502^{*}$ & $74.631^{*}$ & 0.376 & -0.89 & 0.0995 \\
Rrs20 & $-0.427 *$ & $69.880^{*}$ & 0.307 & -0.89 & 0.0907 \\
DRrs5-Rrs20 & $-0.0229 *$ & NA & 0.3866 & -0.65 & 0.0861 \\
Xrs5 & $0.309^{*}$ & $-42.906 \dagger$ & -0.185 & 0.85 & 0.0709 \\
Xrs10 & $0.220 \dagger$ & -23.295 & -0.139 & 0.80 & 0.0544 \\
Xrs15 & 0.147 & $-31.523 \dagger$ & 0.041 & 0.79 & 0.0541 \\
Xrs20 & 0.072 & $-31.781^{*}$ & 0.168 & 0.79 & 0.0423 \\
Fres & -0.308 & $2542.196 *$ & 0.791 & -0.76 & 2.8344 \\
AX & -2.345 & $640.548^{*}$ & -1.212 & -0.83 & 0.8207
\end{tabular}

Each equation corresponds to: $\operatorname{IOS}$ variable $=\mathrm{A} \times(\log$ of age in years $)+\mathrm{B} \times(1 /$ height in $\mathrm{cm}$ ) $+\mathrm{C}$, excepting DRrs5 $-\operatorname{Rrs} 20=\mathrm{A} \times$ (age in years $)+\mathrm{C}$. The $\mathrm{z}$ score for an

individual subject can be calculated through the formula: $\mathrm{z}$ score $=$ (observed value - predicted value)/RSD.

$* P<.01$.

$\dagger P<.05$.

IOS = impulse oscillometry system

$\mathrm{RSD}=$ standard deviation of residuals

$\mathrm{r}=$ correlation coefficient

$\mathrm{Zrs}=$ respiratory system impedance, followed by the frequency at which measured $(5,10,15$, or $20 \mathrm{~Hz}$ ), all expressed in $\mathrm{kPa} / \mathrm{L} / \mathrm{s}$

$\operatorname{Rrs}=$ respiratory system resistance, followed by the frequency at which measured $(5,10,15$, or $20 \mathrm{~Hz}$ ), all expressed in $\mathrm{kPa} / \mathrm{L} / \mathrm{s}$

DRrs5 - Rrs20 = difference of Rrs5 minus Rrs20, in $\mathrm{kPa} / \mathrm{L} / \mathrm{s}$

$\mathrm{NA}=$ not applicable

$\mathrm{Xrs}=$ respiratory system reactance, followed by the frequency at which measured $(5,10,15$, or $20 \mathrm{~Hz}$ ), all expressed in $\mathrm{kPa} / \mathrm{L} / \mathrm{s}$

Fres $=$ resonant frequency, in $\mathrm{Hz}$

$\mathrm{AX}=$ area of reactance, in $\mathrm{kPa} / \mathrm{L}$

by the narrower age range studied by these authors (up to the age of $10 \mathrm{y}$ ). However, in the study by Dencker et al ${ }^{16}$ with a maximum age of $11 \mathrm{y}$ in their study population, a curvilinear association between height and IOS was found, and this curvilinear fit was more accentuated in the study by Nowowiejska et al, ${ }^{17}$ who, in their analysis, included subjects up to $19 \mathrm{y}$ of age. The downward trend of Rrs as age advances could be explained by progressive widening of the tracheobronchial tree during childhood, which is expected to stabilize in early adulthood.

Our study fully agrees with those of other authors concerning the utmost relevance of height in determining IOS values. ${ }^{12,13,15-17}$ Only a few studies have included in their reference equations additional anthropometric variables such as age ${ }^{13}$ and weight, ${ }^{16}$ probably due to the obvious colinearity between these variables. However, through multivariate analysis, we found that, in the majority of IOS indices, a better fit was achieved by introducing age into the regression model; thus, this variable was also used in the final equations. Independently from height, the addi- 

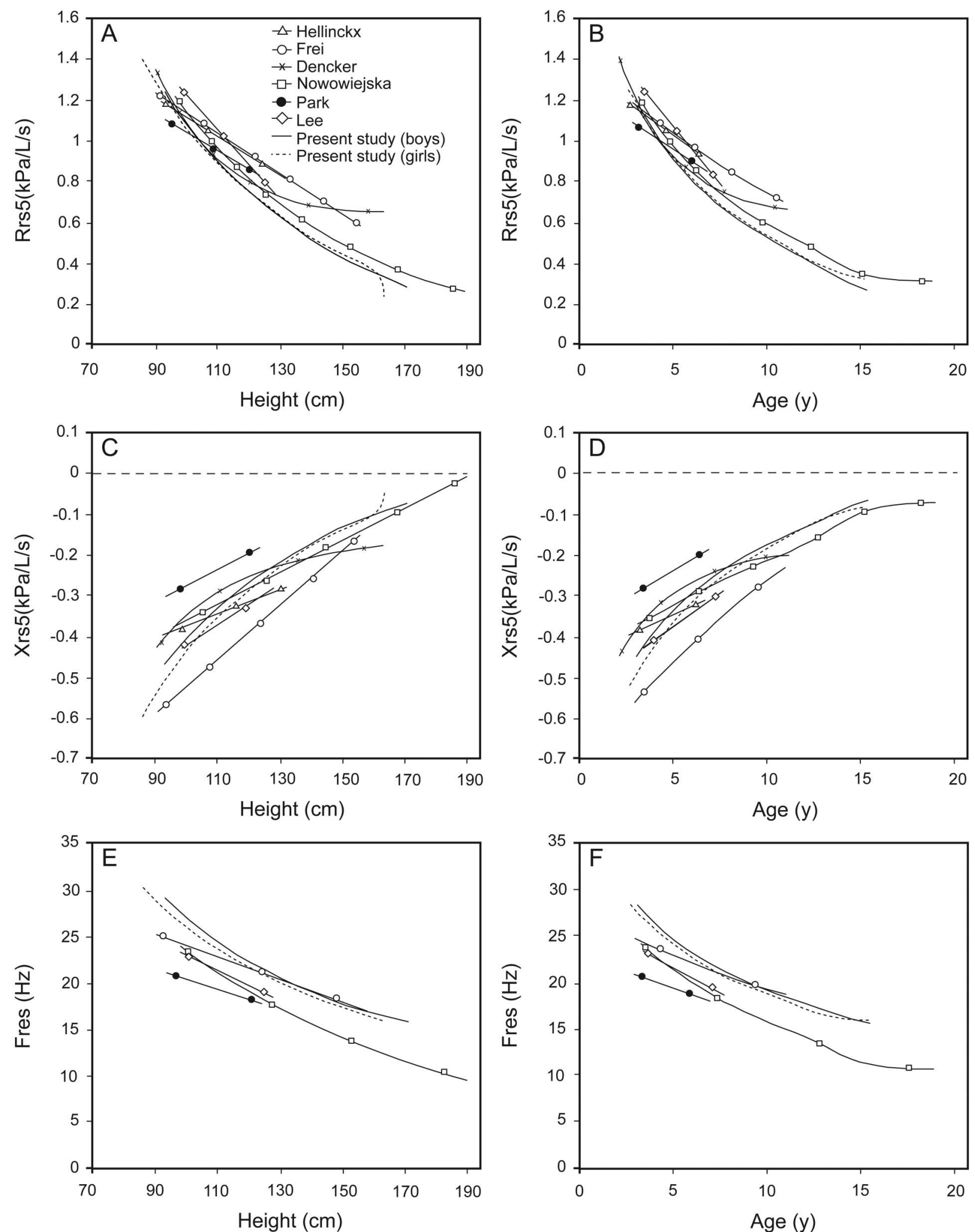

Fig. 2. Regression lines for boys and girls obtained in the present study and those already reported by several authors (for both genders). The ideal (50th percentile) height-for-age and weight-for-age published by the Centers for Disease Control and Prevention were used in those equations including more than one anthropometric variable. Note that, according to our regression lines, when adolescent girls attain their final adult height (around $163 \mathrm{~cm}$ ), age then becomes the more relevant influence, causing further modifications in respiratory system resistances (Rrs5) and reactances (Xrs5) at $5 \mathrm{~Hz}$ (A and C, respectively). 


\section{Impulse Oscillometry in Healthy Children and Adolescents}

tional mechanism by which age can modify lung function is not clear, but it must be kept in mind that, once adult height is reached by the subject, the main variable determining further changes in lung function is age.

Our results indicated that subtle differences existed in several IOS variables between males and females; thus, the sets of reference values were calculated separately for each gender. In previous studies, Park et $\mathrm{al}^{12}$ and Nowowiesjka et al $^{17}$ also presented reference values for boys and girls separately, although no mention was made concerning how large or how close to statistical significance those differences were. In our study, this slight gender difference was more noticeable in older subjects in the case of respiratory resistances, and in the younger population for respiratory reactances (as observed in the supplementary materials at http://www.rcjournal.com). According to our results, adolescent girls tended to have greater respiratory resistance than adolescent boys. Some studies have shown that respiratory resistances in adults are greater in women, as compared with men, ${ }^{18,19}$ and thus it is possible that adolescence constitutes the age at which these gender differences in lung function are being established.

In agreement with most published studies, we found high intrameasurement variability in some IOS variables, especially Xrs, AX, and DRrs5 - Rrs20. The physiological basis of this variability remains unclear, but it may be related with rapid changes in neural control of airway caliber, as we have proposed previously for the high variability of airway resistance measured by the interrupter technique. ${ }^{20}$ On the other hand, evaluation of short-term variability showed that Rrs and Zrs had a tendency to be lower in the second IOS measurement obtained $30 \mathrm{~min}$ after the first maneuver. It is known that stressful tasks such as speaking in public, performing a school examination, or viewing unpleasant scenes give rise to an increased respiratory resistance, mainly in central airways. ${ }^{21,22}$ Thus, it is possible that the emotional stress produced by the first IOS procedure itself was accompanied by a mild degree of airway obstruction, which was partially alleviated in the second IOS maneuver. The further lowering of Rrs 20 after 15 days could well reflect a much lower degree of stress in the subject. Finally, it must be noted that, in our study, the increased values of DRrs5 - Rrs20 observed at day 15 were due to this lowering of Rrs20 and not to an increase of Rrs5, which was stable. This is relevant because an increment of DRs5-Rs20 has been proposed to be indicative of heightened peripheral airway resistance, ${ }^{23-25}$ and, as our study suggests, this is not always true, because a relevant decrease of central airways resistance could also modify DRrs5 - Rrs20 in the same direction.

A consensus panel on pulmonary function tests recommended that, in a given subject, IOS results be reported as a $\mathrm{z}$ score, a value that indicates how many standard deviations the individual is below or above the predicted mean for any given parameter. ${ }^{9}$ In our reference population, once the multivariate regression was constructed for each IOS variable, the residual or error of each value was calculated with the difference between observed and predicted values. The standard deviation of these residuals (RSD), which closely reflects the standard error of the regression, can be used to calculate the $\mathrm{z}$ score of an individual subject through the formula $\mathrm{z}=($ observed value - predicted value $) / \mathrm{RSD}$.

\section{Conclusions}

In the present study, we obtained equations for calculating the reference values of each IOS variable. All IOS variables were strongly associated with height; however, in many of these, age also greatly influenced the result. Hence, both anthropometric variables were introduced into the equations. Although these reference values were obtained in a population of Mexican children and adolescents, it is probable that our results can be also applicable to other Latin American populations sharing the same ethnic background.

\section{ACKNOWLEDGMENTS}

We are grateful to Dr. Celia Espinosa-Herrera, on behalf of authorities of kindergarten numbers 14, 24, 107, and 153 of the Instituto de Seguridad y Servicios Sociales de los Trabajadores del Estado (ISSSTE); to Dr. Alma Arzate-Olmos, on behalf of the Coordinación de Educación Básica del Estado de México; and to the Colegio Euro and Escuela Miguel Hidalgo for their valuable support of this study.

\section{REFERENCES}

1. Smith HJ, Reinhold P, Goldman MD. Forced oscillation technique and impulse oscillometry. Eur Respir Mon 2005;31:72-105.

2. Kaczka DW, Dellacá RL. Oscillation mechanics of the respiratory system: applications to lung disease. Crit Rev Biomed Eng 2011; 39(4):337-359.

3. Vink GR, Arets HG, van der Laag J, van der Ent CK. Impulse oscillometry: a measure for airway obstruction. Pediatr Pulmonol 2003;35(3):214-219.

4. Kim HY, Shin YH, Jung da W, Jee HM, Park HW, Han MY. Resistance and reactance in oscillation lung function reflect basal lung function and bronchial hyperresponsiveness respectively. Respirology 2009;14(7):1035-1041.

5. Komarow HD, Skinner J, Young M, Gaskins D, Nelson C, Gergen PJ, Metcalfe DD. A study of the use of impulse oscillometry in the evaluation of children with asthma: analysis of lung parameters, order effect, and utility compared with spirometry. Pediatr Pulmonol 2012;47(1):18-26.

6. Yamaguchi M, Niimi A, Ueda T, Takemura M, Matsuoka H, Jinnai $\mathrm{M}$, et al. Effect of inhaled corticosteroids on small airways in asthma: investigation using impulse oscillometry. Pulm Pharmacol Ther 2009;22(4):326-332.

7. Shi Y, Aledia AS, Galant SP, George SC. Peripheral airway impairment measured by oscillometry predicts loss of asthma control in children. J Allergy Clin Immunol 2013;131(3):718-723. 


\section{Impulse Oscillometry in Healthy Children and Adolescents}

8. Stanojevic S, Wade A, Stocks J. Reference values for lung function: past, present and future. Eur Respir J 2010;36(1):12-19.

9. Beydon N, Davis SD, Lombardi E, Allen JL, Arets HG, Aurora P, et al. An official American Thoracic Society/European Respiratory Society statement: pulmonary function testing in preschool children. Am J Respir Crit Care Med 2007;175(12):1304-1345.

10. Marchal F, Hall GL. Forced oscillation technique. Eur Respir Mon 2010;47:121-136.

11. Oostveen E, MacLeod D, Lorino H, Farré R, Hantos Z, Desager K, et al. The forced oscillation technique in clinical practice: methodology, recommendations and future developments. Eur Respir J 2003; 22(6): 1026-1041.

12. Park JH, Yoon JW, Shin YH, Jee HM, Wee YS, Chang SJ, et al. Reference values for respiratory system impedance using impulse oscillometry in healthy preschool children. Korean J Pediatr 2011; 54(2):64-68.

13. Lee JY, Seo JH, Kim HY, Jung YH, Kwon JW, Kim BJ, et al. Reference values of impulse oscillometry and its utility in the diagnosis of asthma in young Korean children. J Asthma 2012;49(8): 811-816.

14. Hellinckx J, De Boeck K, Bande-Knops J, van der Poel M, Demedts M. Bronchodilator response in 3-6.5 years old healthy and stable asthmatic children. Eur Respir J 1998;12(2):438-443.

15. Frei J, Jutla J, Kramer G, Hatzakis GE, Ducharme FM, Davis GM. Impulse oscillometry: reference values in children 100 to $150 \mathrm{~cm}$ in height and 3 to 10 years of age. Chest 2005;128(3):1266-1273.

16. Dencker M, Malmberg LP, Valind S, Thorsson O, Karlsson MK, Pelkonen A, et al. Reference values for respiratory system impedance by using impulse oscillometry in children aged 2-11 years. Clin Physiol Funct Imaging 2006;26(4):247-250.
17. Nowowiejska B, Tomalak W, Radliński J, Siergiejko G, Latawiec W, Kaczmarski M. Transient reference values for impulse oscillometry for children aged 3-18 years. Pediatr Pulmonol 2008;43(12): 1193-1197.

18. Aarli BB, Eagan TM, Ellingsen I, Bakke PS, Hardie JA. Reference values for within-breath pulmonary impedance parameters in asymptomatic elderly. Clin Respir J 2013;7(3):245-252.

19. Newbury W, Crockett A, Newbury J. A pilot study to evaluate Australian predictive equations for the impulse oscillometry system. Respirology 2008;13(7):1070-1075.

20. Gochicoa LG, Thomé-Ortiz LP, Furuya ME, Canto R, Ruiz-García ME, Zúñiga-Vazquez G, et al. Reference values for airway resistance in newborns, infants and preschoolers from a Latin American population. Respirology 2012;17(4):667-673.

21. McQuaid EL, Fritz GK, Nassau JH, Lilly MK, Mansell A, Klein RB. Stress and airway resistance in children with asthma. J Psychosom Res 2000;49(4):239-245.

22. Ritz T, Kullowatz A, Goldman MD, Smith HJ, Kanniess F, Dahme B, Magnussen $\mathrm{H}$. Airway response to emotional stimuli in asthma: the role of the cholinergic pathway. J Appl Physiol 2010;108(6): 1542-1549.

23. Goldman MD, Saadeh C, Ross D. Clinical applications of forced oscillation to assess peripheral airway function. Respir Physiol Neurobiol 148(1-2):179-194, 2005.

24. Oppenheimer BW, Goldring RM, Herberg ME, Hofer IS, Reyfman PA, Liautaud S, et al. Distal airway function in symptomatic subjects with normal spirometry following World Trade Center dust exposure. Chest 2007;132(4):1275-1282.

25. Takeda T, Oga T, Niimi A, Matsumoto H, Ito I, Yamaguchi M, et al. Relationship between small airway function and health status, dyspnea and disease control in asthma. Respiration 2010;80(2):120-126. 